\title{
Hiccup: Mystery, Nature and Treatment
}

\author{
Full-Young Chang* and Ching-Liang Lu
}

Environmental Health and Safety Office, Division of Gastroenterology, Taipei Veterans General Hospital, National Yang-Ming University School of Medicine, Taipei, Taiwan

Hiccup is the sudden onset of erratic diaphragmatic and intercostal muscle contraction and immediately followed by laryngeal closure. The abrupt air rush into lungs elicits a "hic" sound. Hiccup is usually a self-limited disorder; however, when it is prolonged beyond 48 hours, it is considered persistent whereas episodes longer than 2 months are called intractable. A reflex arc involving peripheral phrenic, vagal and sympathetic pathways and central midbrain modulation is likely responsible for hiccup. Accordingly, any irritant in terms of physical/chemical factors, inflammation, neoplasia invading the arc leads to hiccups. The central causes of hiccup include stroke, space occupying lesions and injury etc, whereas peripheral causes include lesions along the arc such as tumors, myocardial ischemia, herpes infection, gastroesophageal reflux disease and applied instrumentations on human body etc. Besides, various drugs (eg, anti-parkinsonism drugs, anesthetic agents, steroids and chemotherapies etc) are the possible etiology. An effective treatment of persistent hiccup may be established upon the correct diagnosis of lesion responsible for the serious event. The pharmacotherapy of hiccup includes chlorpromazine, gabapentin, baclofen, serotonergic agonists, prokinetics and lidocaine. Non-pharmacological approaches such as nerve blockade, pacing, acupuncture and measures to hold breathing are also successful. Finally, alternative medicines and remedies are convenient to treat hiccups with uncertain effect. In conclusions, hiccup is likely to result from lesions involving the hiccup reflex arc. The lesion may need to be localized correctly for ablative treatment in patients with intractable hiccup. Apart from lesion ablation, drugs acting on reflex arc may be effective, while some other conventional measures may also be tried.

(J Neurogastroenterol Motil 2012;18:123-130)

\section{Key Words}

Complementary therapies; Gabapentin; Hiccup; Myoclonus; Reflex arc

\section{Introduction}

Both functional belching and hiccup are abnormal physiological behavior activated by the air movement. Functional belching results from venting of excessive gas from stomach and it is often accompanied with gastroesophageal reflux disease (GERD). ${ }^{1}$ It belongs to one of the functional gastrointestinal disorders. In contrast, hiccup is the sudden onset of erratic diaphragmatic and intercostal muscular myoclonus which are followed immediately by laryngeal closure, hence the abrupt air rush into lungs induces the vocal cords to close leading to a "hic" sound. ${ }^{2,3}$ Hiccup or singultus is derived from the Latin word singult, which means "the act of catching one's breath while sobbing." ${ }^{4}$

Hiccup occurrence is not only confined to the adults but also observed among the infants ${ }^{5,6}$ and children. ${ }^{7}$ It is usually a self-limited disorder meaning many episodes would subside spontaneously without any clinical significance. The self-limited

Received: December 22, 2011 Revised: February 1, 2012 Accepted: February 10, 2012

(c) This is an Open Access article distributed under the terms of the Creative Commons Attribution Non-Commercial License (http://creativecommons. org/licenses/by-nc/3.0) which permits unrestricted non-commercial use, distribution, and reproduction in any medium, provided the original work is properly cited.

*Correspondence: Full-Young Chang, MD

Environmental Health and Safety Office, Taipei Veterans General Hospital, 201 Shih-Pai Road, Section 2, Taipei 11217, Taiwan

Tel: +886-2-2875-7308, Fax: +886-2-2875-7310, E-mail: changfy@vghtpe.gov.tw

Financial support: This manuscript was supported from a grant of Taipei Veterans General Hospital (Grant No. V1-100C1-092).

Conflicts of interest: None. 
hiccup is believed to be induced by the rapid stomach distension and irritation in terms of overeating, eating too fast, ingesting spicy food, drinking carbonated drinks, aerophagia and sudden change in ingested food temperature (eg, hot or cold drinks, a cold water shower, using alcohol and excessive smoking etc). ${ }^{8}$ Persistent hiccup means episode lasting for 48 hours or more, whereas those longer than 2 months are considered intractable., ${ }^{2,9}$ Severe and prolonged hiccup may lead to exhaustion, fatigue, malnutrition, weight loss, dehydration and even death in the extreme situations. ${ }^{8,9}$ Since hiccup has a neurological reflex arc consisting of peripheral pathways and central midbrain modulation, patients with intractable hiccups are likely to have structural or functional irritation involving the reflex arc. ${ }^{2,3,9}$

Unfortunately, there is no guideline available to direct treating this serious disorders effectively. Chlorpromazine is approved by the US Food and Drug Administration as the only drug to treat hiccup until now. ${ }^{2}$ However, using chlorpromazine to treat hiccup without correct diagnosis of lesion responsible for hiccup may lead to missing potentially serious conditions that may cause this symptom. Literature suggests that measures ranging from conventional remedies, alternative medicines to emerging therapies may treat hiccups successfully. ${ }^{2}$ The authors attempt to review current understanding of pathophysiology and management of hiccup.

\section{Pathophysiology}

The pathophysiological mechanism of hiccup is related to lesions in its reflex arc shown in Figure. The hiccup reflex arc consists of 3 components, the afferent limb including phrenic, vagus and sympathetic nerves to convey somatic and visceral sensory signals, the central processing unit in the midbrain and the effer-

\section{Stimulation (central, peripheral) via afferent limb uploading to}

Brain: central processing

Efferent limb to diaphragm, respiratory mucles

Figure. The putative hiccup reflex arc. It includes afferent limb to receive stimulation either located in the central nervous system or from peripheral lesions, central brain processing and efferent limb to convey responded signals to the diaphragm and respiratory muscles. Adapted from Takahashi et al. ${ }^{11}$ ent limb traveling in motor fibers of phrenic nerves to diaphragm and accessory nerves to the intercostal muscles, respectively. ${ }^{2,10,11}$ Central process of hiccup remains poorly understood, it may not only be confined to the medulla but may also involve other parts of central nervous system (CNS) located between brainstem and cervical spine. ${ }^{2}$ The hiccup central component usually refers to chemoreceptors probably located in the peri-aqueductal gray matter and sub-thalamic nuclei. ${ }^{10}$ Among the neurotransmitters involved in the process of hiccup, both dopamine (D) and gamma-aminobutyric acid (GABA) have been documented. ${ }^{2}$ The above pathophysiological basis explains why some inhibitors of these substances may be employed in treatment of hiccup. Accordingly, any physical and chemicals irritants and inflammatory and neoplastic conditions involving the hiccup reflex may cause hiccup. In addition, hiccup may be transient in many patients as spontaneous resolution of the stimuli that caused it might lead to its disappearance. ${ }^{8}$ Unfortunately, owing to the long trajectory of afferent and efferent nerves and the diffuse central processes involving the hiccup reflex arc, the accurate diagnosis of lesions in the arc and trying to terminate the pathological processes in the intractable events are often very difficult. ${ }^{8}$ As several types of lesion located along the hiccup reflex arc may cause it, hiccup is common and has been described as case reports in association with several conditions and has been treated with various types of treatment, which might confuse readers.

\section{Etiology of Persistent and Intractable Hiccups}

In the review of recent literature, too many causes of hiccups have been reported. Some are well known to invade the hiccup reflex arc, whereas many others remain unexplained why they would elicit persistent or intractable hiccups since no obvious invasion to the hiccup reflex pathway was confirmed. According to the sites of lesion, hiccup may originate either from central or peripheral pathways. Briefly, Table 1 summarizes the reported etiology of persistent and intractable hiccups. Their details are further illustrated in the following.

\section{Cerebral Vascular Accidents}

Brain ischemia or stroke is not rare among the individuals with intractable hiccup and in some patients cerebrovascular cause was correctly diagnosed months later. ${ }^{11-13}$ If a correct diagnosis is made, intractable hiccup may resolve after initiation of anticoagulant therapy. ${ }^{14}$ In addition, hiccup did occur in the patient 
Table. Reported Etiology of Persistent and Intractable Hiccups

\begin{tabular}{ll}
\hline \multicolumn{1}{c}{ Lesion site/Type } & \multicolumn{1}{c}{ Disease/Disorder } \\
$\begin{array}{l}\text { Central nervous system } \\
\text { Vascular disease }\end{array}$ & $\begin{array}{l}\text { Stroke, infarct, systemic lupus erythematosus related vascular disorders and aneurysms } \\
\text { Tumor }\end{array}$ \\
$\begin{array}{l}\text { Astrocytoma, carvenoma and brain stem tumors } \\
\text { Trflammation }\end{array}$ & Neuromyelitis optica and multiple sclerosis \\
Mrauma & Brain injury \\
Periphellaneous & Seizure, cranial nervous herpes infection and parkinsonism \\
Chest cavity & Mediastinal diseases, lymphadenopathy and diaphragmatic tumors \\
Heart & Myocardial ischemia \\
Gastrointestinal tract & Esophageal tumors, gastroesophageal reflux diseases, stomach volvulus and H. pylori infection \\
Lower abdomen & Gynecologic tumors \\
Miscellaneous & Cancers \\
Procedure & Anesthetic agents and post-operative disturbances \\
Surgery & Chemotherapeutic agents and steroids \\
Chemotherapy & Anti-parkinsonism treatment, psychiatric medications, azithromycin and morphine \\
Drugs & Atrial pacing, catheter ablation, central venous catheterization, esophageal stent placement, bronchoscopy, tracheostomy \\
Instrumentation & and shaving beards \\
& Electrolyte imbalance, ethanol users, tuberculosis and chronic renal failure \\
Miscellaneous &
\end{tabular}

H. pylori, Helicobacter pylori.

with systemic lupus erythematosus related to medulla infarct, which was successfully treated with corticosteroid. ${ }^{15}$ Steroid was also useful in a patient with systemic lupus erythematosus and hiccup related to vasogenic edema due to aseptic meningitis confirmed on imaging. ${ }^{16}$ Briefly, clinicians should consider the probability of CNS ischemia/stroke among aged people or subjects with vascular disease presenting with persistent or intractable hiccup to avoid delay in diagnosis and initiation of ineffective treatment.

\section{Central Nervous System Tumors, Injury and Inflammatory Diseases}

There is no doubt that any space occupying lesion in the brain has the chance to elicit hiccup. The reported brain tumors to induce serious hiccups included astrocytoma, cavernoma and brain stem tumors etc. ${ }^{17-19}$ Therefore, these hiccups usually resolved after surgical resection of the brain lesions. ${ }^{17}$ Cerebellar artery aneurysm also reported to result in hiccup and that was effectively treated after surgery. ${ }^{20}$ Brain injury may cause intractable hiccup. ${ }^{21}$ It is apparent that a carefully taken history regarding CNS is very important when we encounter these subjects with persistent or intractable hiccup. Apart from other brain stem symptoms like nausea and vomiting, neuromyelitis optica may cause intractable hiccup because this disease is an inflammatory disease involving optic nerves and spinal cord. It is indicated that half of them had brain stem symptoms, while prolonged hiccup occurred in $17 \%-66 \%$ of victims during the illness. ${ }^{22,23}$ Hiccup is considered as one form of infant seizure related manifestations. Unfortunately, it persisted in spite of subsidence of other seizure symptoms. ${ }^{5}$

\section{Lesions Along the Peripheral Neuro-pathways}

A patient with mediastinal lymph node sarcoidosis, which was likely the lesion invading the hiccup reflex arc, had persistent hiccup that did not respond to steroid therapy. ${ }^{24} \mathrm{~A}$ tumor infiltration on the diaphragm was considered as the obvious cause of intractable hiccup. ${ }^{25}$ A patient with herpes zoster involving cranial nerve neurons including the vagus nerve presented with intractable hiccup and diaphragmatic paralysis; acyclovir treatment effectively ameliorated hiccup in this patient. ${ }^{26}$ Hiccup has been an unrecognized symptom of esophageal cancer. In a large series of 99 patients with esophageal tumors originating from any parts of esophagus, $27 \%$ had persistent hiccup longer than 48 hours. ${ }^{27}$ The hiccup might be either due to primary effect of tumor or secondary to dilatation of esophagus above the stenotic lesion associated with raised intra-luminal pressure eliciting a reflex activity. ${ }^{27}$ Hiccup was reported as a subtle sign of stomach volvulus and was probably induced by the diaphragmatic irritation 
from the distended stomach. ${ }^{28}$ Interestingly, myocardial ischemia has been one of unusual reasons for intractable hiccups. For example, some myocardiac ischemia-related intractable cases were effectively treated using either coronary intervention or acupuncture. ${ }^{29,30}$ Perhaps, the disorder is elicited by released factors from ischemic tissues with action on the hiccup arc or ischemic injury of the sensory branches in pleura, pericardium and peritoneum, which also send signal to the phrenic nerves. ${ }^{29,30}$ Hence, myocardial ischemia can also cause vagal and phrenic nerve irritation.

\section{Gastrointestinal and Abdominal Disorders}

It is well known that GERD is commonly associated with belching. Apart from the main reflux symptoms in terms of acid regurgitation, heartburn, globus, dysphagia and hoarseness etc, hiccup was not rare among the GERD patients. ${ }^{31}$ Even it may be underestimated among the GERD patients, a case series indicated that $7.9 \%$ male and $10 \%$ female $(P<0.05)$ GERD patients had hiccup episodes. ${ }^{32}$ In addition, acid infusion as a provocative test did confirm the GERD related hiccup, while some prolonged hiccups also responded well to the proton pump inhibitors. ${ }^{33,34}$ Since severe belching may sometime precede the hiccup episode, perhaps belching is the mechanism leading to hiccup among the GERD subjects. ${ }^{35}$ It is also unbelievable that Helicobacter pylori infection was indicated as a cause of hiccup, which was confirmed via successful bacterial eradication. The putative pathogenesis might be related to increased acid production following $H$. pylori infection that might stimulate esophageal mucosa irritating vagal afferents. ${ }^{36}$

\section{Anesthetic and Post-operative Hiccups}

Post-operative hiccups were reported in subjects receiving various surgeries, for example, Whipple operation and colectomy. Of them, surgery related gastroparesis was suggested as one of the mechanisms leading to the hiccups. ${ }^{8,37}$ On the other hand, using anesthetic agents in surgery may be associated with hiccups. For example, propofol induction during anesthesia induced hiccups. ${ }^{38}$ Even an epidural anesthesia using bupivacaine led to repeated hiccup in a patient. The addressed mechanisms included the interruption of inhibitory reflex of phrenic nerve motor drives and direct de-afferentation of visceral sensory pathway resulting in increased diaphragmatic activities and hiccups. ${ }^{39,40}$ An infant using epidural ropivacaine in a fistula surgery developed persistent hiccup in a dose dependent manner and it rapidly subsided in a low dose infusion. ${ }^{6}$ Overall, it is uncertain whether some cases of post-operative hiccups are the effect of direct surgery or secondary to anesthetic agents.

\section{Hiccups in Patients With Cancer and on Che- motherapy}

Serious hiccup is not unusual among the cancer patients. For instance, an Italian report indicated that $3.9 \%$ in-patients and $4.5 \%$ out-patients had severe chronic hiccup. ${ }^{41}$ Among some patients with cancer, hiccup might be secondary to chemotherapy. A retrospective analysis pointed out that hiccups occurred among $0.39 \%$ of chemotherapy treated patients including cisplatin, carboplatin and etoposide etc, particularly among males. ${ }^{42}$ Cisplatin is often the offending agent inducing hiccup; the postulated mechanism includes initiation of an emetic reflex by releasing 5 -hydroxyltryptamine (HT) from the enterochromaffin cells and vagal afferents. Because vagus nerve is one of the afferents of hiccup reflex arc, using cisplatin often initiates hiccup reflex. ${ }^{43}$ Clinically, the occurrences of hiccups among the Japanese patients receiving various doses of cisplatin therapy ranged from $6.1 \%$ to $10 \%$. $^{44}$ Besides, a prospective trial conducted in Taiwan showed that hiccups developed among $41.2 \%$ patients using both combination of cisplatin and dexamethasone therapy, and $97.4 \%$ of the victims were male patients. Consequently, the authors suggested that steroid could induce hiccup when combined with cisplatin therapy synergistically because steroid receptors are likely to exist within the efferent limbs of hiccup reflex. ${ }^{43}$ Similarly, hiccups did occur among various steroid users. ${ }^{45,46}$ In some instances, etiological relationship between steroid use and hiccup was established by discontinuation of steroid therapy, which ameliorated hiccup. Alternatively, steroid when combined with ramosetron could be effective in preventing the chemotherapy related hiccups. ${ }^{47}$ In fact, steroid is listed as one of the recommended agents to treat hiccups. ${ }^{8}$ Steroid may behave as two sides of a knife either by inducing serious hiccup or by preventing it when combined with some other drugs.

\section{Other Drugs Inducing Hiccups}

Twenty percent of parkinsonism (PD) patients had frequent hiccups compared to $3 \%$ of the controls. Even in some patients, PD was diagnosed after occurrence of intractable hiccups. Replacement therapy with dopamine agonists in PD patients is considered to induce certain episodes of hiccup; however, in others, hiccup may occur as the non-motor symptom of PD rather than as side effect of anti-PD treatment. ${ }^{48}$ The pathogenesis is believed to be related to the fact that dopamine agonists share a 
high affinity for $\mathrm{D}_{3}$ receptors which may be involved in the hiccup reflex arc. ${ }^{49}$ Hence, the drugs to block dopaminergic neurotransmission including chlorpromazine and metoclopramide may be employed in treating hiccup episodes. ${ }^{48}$ Psychiatric medications may also induce hiccups. Aripiprazole, a partial agonist at the $\mathrm{D}_{2}, \mathrm{D}_{3}$ receptors and $5-\mathrm{HT}_{1 \mathrm{~A}}$ receptors, is used to stabilize dopamine and serotonin systems through these receptors. A patient was confirmed to manifest hiccup after using this agent because discontinuation was followed by quick symptom resolution within hours. ${ }^{50}$ Intractable hiccup also subsided after discontinuation of oral azithromycin and intra-thecal morphine administration. It is hypothesized that azithromycin activates vagal mechanism leading to hiccup. ${ }^{51}$ Regarding the latter case, the replacement of hydromorphone did not induce hiccup although both drugs almost shared the similar structure with little difference. ${ }^{52}$ In summary, in patients with intractable hiccup, drug history should be carefully reviewed as discontinuation of offending drugs may dramatically resolve hiccup.

\section{Instrumentation Related Hiccups}

Interestingly, many measures on human body have been known to elicit serious hiccups. Of them, mechanical irritation of phrenic nerves via various measures is well-known. Because the right phrenic nerve is a branch of cervical plexus with close contact to the right atrium, atrial pacing for brady-arrhythmia and catheter ablation for atrial fibrillation were reported to induce diaphragmatic contractions and hiccups. ${ }^{53,54}$ Similar cardiovascular measures such as central venous catheter advancing up to the right ventricle also induced serious hiccups. ${ }^{55} \mathrm{~A}$ patient with esophago-gastric junction tumor developed intractable hiccup after placing esophageal stent, which was likely related to irritation of afferents of hiccup reflux arc. ${ }^{56}$ The procedures upon respiratory tract, for example, bronchoscopy and tracheostomy were also reported to cause serious hiccups. ${ }^{7,57}$ Although the authors never addressed the possible mechanisms, they were similar to those with esophageal lesions and instrumentations. Healthy men shaving or stroking their chins had triggered an acute explosive hiccup. ${ }^{58}$ This might be explained by the fact that the sensory afferents from chin convey signal to the intermediate part of spinal tract nucleus of fifth nerve, which also projects to the medullary reticular formation that interplay with the phrenic nucleus and nucleus ambiguous, which are involved in centrally mediated hiccup. Other miscellaneous causes of hiccup include electrolyte imbalance, tuberculosis infection, ethanol users and chronic renal failures etc. ${ }^{59}$

\section{Treatment of Hiccups}

Basically, transient hiccups are self-limited, and neither etiological evaluation nor immediate treatment is needed for these subjects unless their hiccup recurs. The effective hiccup treatment is exactly established upon a correct diagnosis of lesion responsible for the serious event. For example, after effective measures were undertaken to CNS lesions such as vascular ischemia and tumors, hiccup episodes subsided. Similarly, some peripheral lesions related hiccups responded well after these lesions were ablated. In addition, many available therapies are not evidence-based; moreover, alternative medicines and remedies have been tested with unbelievable effectiveness.

\section{Drug Treatment}

Apart from the well-known chlorpromazine approved to treat hiccups, many other drugs have been tested and recommended. For example, anticonvulsants in various preparations are indicated to treat intractable hiccups. Gabapentin, an alpha-2-delta ligand with structural similarity to GABA and the ability to block voltage-operated calcium channels to reduce release of several neurotransmitters including glutamate and substance $\mathrm{P}$ and $\mathrm{fi}_{1}$ nally to modulate the diaphragmatic activity, was promising and safe to treat intractable hiccups. ${ }^{25,41,60}$ Overall, the response rates of gabapentin ranged from $66.7 \%$ to $88.4 \%$. Reported side effect of gabapentin is sleepiness. ${ }^{41}$ Baclofen, a GABA derivative, has been used to treat hiccup due to CNS tumors and chronic renal failure. ${ }^{19,59}$ However, baclofen should be used very cautiously in elderly subjects and those with renal failure because of the side effects such as nephrotoxicity, over sedation, ataxia and confusion. $^{59,61}$ Carvedilol, a potent non-cardio selective beta-blocker, calcium channel blocker and antioxident used to treat tardive dyskinesia of chorea, was also tried in intractable hiccup effectively. ${ }^{62}$ Besides, 5-HT agonist, for example, tandospirone (affinity to $5-\mathrm{HT}_{1 \mathrm{~A}}$ ) was also promising to treat stroke related hiccup because of direct inhibition of phrenic nerve activity via centrally located receptors. ${ }^{11}$ Olanzapine, a serotonergic antagonist with action on post-synaptic receptors, was also used to diminish the phrenic motor neuron activity to treat hiccup of a brain injury case. $^{21}$ Midazolam, a benzodiazepine, acts on benzodiazepine receptors to form the benzodiazepine-GABA receptor-chloride ionophore complex in gating chloride channels which leads to hyperpolarization to inhibit neuron firing and to decrease neuronal depolarization. When combined with morphine, midazolam did control the intractable hiccup in a cancer patient. ${ }^{63}$ Amantadine, 
acting as a low-affinity antagonist at the N-methyl-D-aspartate subtype of glutamate receptors, has been used as anti-PD therapy because over-activity of glutamatergic transmission is one of mechanisms leading to PD; this agent was successfully used to treat postoperative hiccup in a cancer patient. ${ }^{8}$ Traditionally, prokinetics have been widely used to treat hiccups because stomach distension is considered as one of the mechanisms leading to hiccups. ${ }^{64}$ In fact, premedicated metoclopramide treatment did effectively prevent the anesthesia induced hiccup. ${ }^{65}$ Lidocaine can stabilize cell membrane by blocking sodium channels to reduce neuronal excitability. It has been used successfully in treating or pre-treating intractable hiccups induced via many measures. ${ }^{57,66,67}$ Other miscellaneous agents used to treat hiccup include calcium channel blockers and antidepressants. ${ }^{8}$

\section{Non-pharmacological Measures to Treat Hic- cups}

Phrenic nerve blockades such as ultrasound guided blocking of efferent limbs, trans-esophageal diaphragmatic pacing and nerve stimulator to confirm the effective blocking were successfully used to treat persistent post-operative and lung cancer related hiccups. ${ }^{37,40,68}$ Even a left vagal afferent blockade via nerve stimulation might be applied to stroke related intractable hiccup after failure of phrenic nerve block. ${ }^{69}$ Ultrasound guided pulsed radiofrequency ablation of phrenic nerve was another option to treat coronary by-pass surgery related hiccup. ${ }^{70}$ Acupuncture has been employed to treat serious hiccups among patients with myocardial infarction and metastatic liver tumor. ${ }^{30,71}$ A control trial confirmed that this procedure was superior over ritaline to treat stroke related hiccups. ${ }^{12}$ The addressed mechanisms of acupuncture procedure are complex which include changed axonal excitability, diminished nociceptive circuits in the dorsal horn, inhibited spinal reflexes, segmental pre- and post-synaptic inhibition mediated by GABA, and activated supra-spinal centers via spinoreticular fibers, and spinothalamic and spinomesencephalic neurons etc. ${ }^{71}$ Similarly, near-infrared irradiation applied on the acupoints to improve the local blood circulation of affected areas has been shown to effectively treat intractable hiccups. ${ }^{13,72}$

\section{Breath Holding and Folk Remedies to Treat Hiccups}

Measures other than the recommended drugs and instrumentation have been used to treat hiccups safely. For example, gag reflex has long been used as an immediate remedy to treat hiccup. The possible mechanism include restoration of normal phrenic nervous rhythms due to artificial and transient stoppage of respiration. ${ }^{3}$ In one patient, an inflated cuff of laryngeal mask airway was used to stimulate the pharynx opposite second cervical vertebra to inhibit hiccup during induction with propofol. ${ }^{38}$ Unfortunately, this procedure was also a trigger to induce hiccups commonly among some subjects. ${ }^{73}$ On the other hand, supramaximal inspiration, a measure consisted of hypercapnia, diaphragm immobilization and positive airway pressure could terminate intractable hiccups in pregnancy via holding diaphragm for more than 20 seconds. ${ }^{74}$ As well as being used to expel aspirated water, debris and vomitus, modified Heimlich maneuver with 3 thrusts delivered at 10 second interval could terminate hiccup immediately with the suggested mechanism of stabilizing diaphragmatic spasm. ${ }^{75}$ Intranasal vinegar instillation to stimulate the dorsal pharynx at the supplied area of afferent branches of hiccup reflex arc was effective in a child with tracheostomy related hiccup. ${ }^{7}$ Finally, other remedies in terms of breathing into a bag, breath holding, swallowing granulated sugar, drinking/gargling iced water, forceful traction of tongue, biting lemon, eating peanut butter, eyeball compression, carotid/rectal massage, Valsava maneuver, fright and gastric lavage etc have long been recommended to treat hiccups for many years. These remedies may be very convenient and less hazardous, however, their effectiveness to treat serious hiccups are usually uncertain. ${ }^{2,3,61}$

\section{Conclusion}

Hiccup usually results from a lesion involving the hiccup reflex arc. Among patients with persistent or intractable hiccup, attempt to identify the lesion causing it is needed since serious or lethal disorder may exist. Apart from lesion ablation, drugs and measures acting on the reflex arc may be effective, while some conventional remedies can be tried while their effects to terminate hiccups are uncertain.

\section{References}

1. Tack J, Talley NJ, Camilleri M, et al. Functional gastroduodenal disorders. Gastroenterology 2006;130:1466-1479.

2. Becker DE. Nausea, vomiting, and hiccups: a review of mechanisms and treatment. Anesth Prog 2010;57:150-156.

3. Kumar A. Gag reflex for arrest of hiccups. Med Hypotheses 2005; 65:1206.

4. Hiccup. Available from URL: http://en.wikipedia.org/wiki/Hiccup (accessed 20 February, 2012).

5. Wallace AH, Manikkam N, Maxwell F. Seizures and a hiccup in the diagnosis. J Paediatr Child Health 2004;40:707-708. 
6. Bagdure DN, Reiter PD, Bhoite GR, Dobyns EL, Laoprasert P. Persistent hiccups associated with epidural ropivacaine in a newborn. Ann Pharmacother 2011;45:e35.

7. Iwasaki N, Kinugasa H, Watanabe A, et al. [Hiccup treated by administration of intranasal vinegar.] No To Hattatsu 2007;39:202205. [Japanese]

8. Wilcox SK, Garry A, Johnson MJ. Novel use of amantadine: to treat hiccups. J Pain Symptom Manage 2009;38:460-465.

9. Howard RS. Persistent hiccups. BMJ 1992;305:1237-1238.

10. Hansen BJ, Rosenberg J. Persistent postoperative hiccups: a review. Acta Anaesthesiol Scand 1993;37:643- 646.

11. Takahashi T, Murata T, Omori M, Tagaya M, Wada Y. Successful treatment of intractable hiccups with serotonin $(5-\mathrm{HT}) 1 \mathrm{~A}$ receptor agonist. J Neurol 2004;251:486-487.

12. Hongliang X, Xuemei C, Shizhao H, Chaofeng L. Acupuncture and cupping for treatment of hiccup in cases of cerebrovascular accident. J Tradit Chin Med 2006;26:175-176.

13. Chang CC, Chang ST, Lin JC, Li TY, Chiang SL, Tsai KC. Resolution of intractable hiccups after near-infrared irradiation of relevant acupoints. Am J Med Sci 2006;332:93-96.

14. Mandalà $\mathrm{M}$, Rufa $\mathrm{A}$, Cerase $\mathrm{A}$, et al. Lateral medullary ischemia presenting with persistent hiccups and vertigo. Int J Neurosci 2010; 120:226-230

15. Delèvaux I, André M, Marroun I, Lamaison D, Piette JC, Aumaître O. Intractable hiccup as the initial presenting feature of systemic lupus erythematosus. Lupus 2005;14:406-408.

16. Sugimoto T, Takeda N, Yamakawa I, et al. Intractable hiccup associated with aseptic meningitis in a patient with systemic lupus erythematosus. Lupus 2008;17:152-153.

17. Redondo-Cerezo E, Viñuelas-Chicano M, Pérez-Vigara G, et al. A patient with persistent hiccups and gastro-oesophageal reflux disease. Gut 2008;57:763, 771.

18. Pechlivanis I, Seiz M, Barth M, Schmieder K. A healthy man with intractable hiccups. J Clin Neurosci 2010;17:781-783.

19. Tay SS, Yadav RR. Novel use of baclofen in cancer patients for the treatment of hiccups. Ann Acad Med Singapore 2010;39:154.

20. Gambhir S, Singh A, Maindiratta B, Jaeger M, Darwish B, Sheridan M. Giant PICA aneurysm presenting as intractable hiccups. J Clin Neurosci 2010;17:945-946.

21. Alderfer BS, Arciniegas DB. Treatment of intractable hiccups with olanzapine following recent severe traumatic brain injury. J Neuropsychiatry Clin Neurosci 2006;18:551-552.

22. Wang KC, Lee CL, Chen SY, Lin KH, Tsai CP. Prominent brainstem symptoms/signs in patients with neuromyelitis optica in a Taiwanese population. J Clin Neurosci 2011;18:1197-1200.

23. Takahashi T, Miyazawa I, Misu T, et al. Intractable hiccup and nausea in neuromyelitis optica with anti-aquaporin-4 antibody: a herald of acute exacerbations. J Neurol Neurosurg Psychiatry 2008;79: 1075-1078.

24. Lin LF, Huang PT. An uncommon cause of hiccups: sarcoidosis presenting solely as hiccups. J Chin Med Assoc 2010;73:647-650.

25. Hernández JL, Pajarón M, García-Regata O, Jiménez V, GonzálezMacías J, Ramos-Estébanez C. Gabapentin for intractable hiccup. Am J Med 2004;117:279-281.

26. Morinaka S. Herpes zoster laryngitis with intractable hiccups. Auris Nasus Larynx 2009;36:606-608.
27. Khorakiwala T, Arain R, Mulsow J, Walsh TN. Hiccups: an unrecognized symptom of esophageal cancer? Am J Gastroenterol 2008;103:801.

28. McElreath DP, Olden KW, Aduli F. Hiccups: a subtle sign in the clinical diagnosis of gastric volvulus and a review of the literature. Dig Dis Sci 2008;53:3033-3036.

29. Krysiak W, Szabowski S, Stepień M, Krzywkowska K, Krzywkowski A, Marciniak P. Hiccups as a myocardial ischemia symptom. Pol Arch Med Wewn 2008;118:148-151.

30. Liu FC, Chen CA, Yang SS, Lin SH. Acupuncture therapy rapidly terminates intractable hiccups complicating acute myocardial infarction. South Med J 2005;98:385-387.

31. Bor S, Mandiracioglu A, Kitapcioglu G, Caymaz-Bor C, Gilbert RJ. Gastroesophageal reflux disease in a low-income region in Turkey. Am J Gastroenterol 2005;100:759-765.

32. Rey E, Elola-Olaso CM, Rodríguez-Artalejo F, Locke GR 3rd, Díaz-Rubio M. Prevalence of atypical symptoms and their association with typical symptoms of gastroesophageal reflux in Spain. Eur J Gastroenterol Hepatol 2006; 18:969-975.

33. Gluck M, Pope CE 2nd. Chronic hiccups and gastroesophageal reflux disease: the acid perfusion test as a provocative maneuver. Ann Intern Med 1986;105:219-220.

34. Pooran N, Lee D, Sideridis K. Protracted hiccups due to severe erosive esophagitis: a case series. J Clin Gastroenterol 2006;40:183-185.

35. Hopman WP, van Kouwen MC, Smout AJ. Does (supra) gastric belching trigger recurrent hiccups? World J Gastroenterol 2010;16: 1795-1799.

36. Orr CF, Rowe DB. Helicobacter pylori hiccup. Intern Med J 2003; 33:133-134.

37. Renes SH, van Geffen GJ, Rettig HC, Gielen MJ, Scheffer GJ. Ultrasound-guided continuous phrenic nerve block for persistent hiccups. Reg Anesth Pain Med 2010;35:455-457.

38. Baraka A. Inhibition of hiccups by the laryngeal mask airway. Anaesthesia 2004;59:926.

39. McAllister RK, McDavid AJ, Meyer TA, Bittenbinder TM. Recurrent persistent hiccups after epidural steroid injection and analgesia with bupivacaine. Anesth Analg 2005;100:1834-1836.

40. Andres DW. Transesophageal diaphragmatic pacing for treatment of persistent hiccups. Anesthesiology 2005;102:483.

41. Porzio G, Aielli F, Verna L, Aloisi P, Galletti B, Ficorella C. Gabapentin in the treatment of hiccups in patients with advanced cancer: a 5-year experience. Clin Neuropharmacol 2010;33:179-180.

42. Takiguchi $Y$, Watanabe R, Nagao R, Kuriyama T. Hiccups as an adverse reaction to cancer chemotherapy. J Natl Cancer Inst 2002;94: 772.

43. Liaw CC, Wang CH, Chang HK, et al. Cisplatin-related hiccups: male predominance, induction by dexamethasone, and protection against nausea and vomiting. J Pain Symptom Manage 2005;30: 359-366.

44. Takahashi T, Hoshi E, Takagi M, Katsumata N, Kawahara M, Eguchi K. Multicenter, phase II, placebo-controlled, double-blind, randomized study of aprepitant in Japanese patients receiving high-dose cisplatin. Cancer Sci 2010;101:2455-2461.

45. Ifran A, Kaptan K, Beyan C. Intractable hiccups may develop with cyclophosphamide infusion. Am J Hematol 2004;77:319-320.

46. Dickerman RD, Overby C, Eisenberg M, Hollis P, Levine M. The 
steroid-responsive hiccup reflex arc: competitive binding to the corticosteroid-receptor? Neuro Endocrinol Lett 2003;24:167-169.

47. Ho CL, Su WC, Hsieh RK, Lin ZZ, Chao TY. A randomized, double-blind, parallel, comparative study to evaluate the efficacy and safety of ramosetron plus dexamethasone injection for the prevention of acute chemotherapy-induced nausea and vomiting. Jpn J Clin Oncol 2010;40:294-301.

48. Miwa H, Kondo T. Hiccups in Parkinson's disease: an overlooked non-motor symptom? Parkinsonism Relat Disord 2010;16:249-251.

49. Lester J, Raina GB, Uribe-Roca C, Micheli F. Hiccup secondary to dopamine agonists in Parkinson's disease. Mov Disord 2007;22: 1667-1668.

50. Ray P, Zia Ul Haq M, Nizamie SH. Aripiprazole-induced hiccups: a case report. Gen Hosp Psychiatry 2009;31:382-384.

51. Jover F, Cuadrado JM, Merino J. Possible azithromycin-associated hiccups. J Clin Pharm Ther 2005;30:413-416.

52. Ruan X, Couch JP, Shah R, Wang F, Liu HN. Persistent hiccup associated with intrathecal morphine infusion pump therapy. Am J Phys Med Rehabil 2007;86:1019-1022.

53. Doshi H, Vaidyalingam R, Buchan K. Atrial pacing wires: an uncommon cause of postoperative hiccups. Br J Hosp Med (Lond) 2008;69:534.

54. Sacher F, Monahan KH, Thomas SP, et al. Phrenic nerve injury after atrial fibrillation catheter ablation: characterization and outcome in a multicenter study. J Am Coll Cardiol 2006;47:2498-2503.

55. Sav T. Hiccups, a rare complication arising from use of a central venous catheter. Hemodial Int 2010;14:337-338.

56. Turkyilmaz A, Eroglu A. Use of baclofen in the treatment of esophageal stent-related hiccups. Ann Thorac Surg 2008;85:328-330.

57. Dunst MN, Margolin K, Horak D. Lidocaine for severe hiccups. N Engl J Med 1993;329:890-891.

58. Todisco T, Todisco C, Bruni L, Donato R. Chin stimulation: a trigger point for provoking acute hiccups. Respiration 2004;71:104.

59. Chou CL, Chen CA, Lin SH, Huang HH. Baclofen-induced neurotoxicity in chronic renal failure patients with intractable hiccups. South Med J 2006;99:1308-1309.

60. Tegeler ML, Baumrucker SJ. Gabapentin for intractable hiccups in palliative care. Am J Hosp Palliat Care 2008;25:52-54.

61. Schuchmann JA, Browne BA. Persistent hiccups during rehabilita- tion hospitalization: three case reports and review of the literature. Am J Phys Med Rehabil 2007;86:1013-1018.

62. Stueber D, Swartz CM. Carvedilol suppresses intractable hiccups. J Am Board Fam Med 2006;19:418-421.

63. Moro C, Sironi P, Berardi E, Beretta G, Labianca R. Midazolam for long-term treatment of intractable hiccup. J Pain Symptom Manage 2005;29:221-223

64. Hiyama T, Yoshihara M, Tanaka S, Haruma K, Chayama K. Effectiveness of prokinetic agents against diseases external to the gastrointestinal tract. J Gastroenterol Hepatol 2009;24:537-546.

65. Stav A, Weksler N, Berman M, et al. Premedication with metoclopramide decreases the frequency of methohexital induced hiccup. J Anesth 1992;6:17-20.

66. Landers C, Turner D, Makin C, Zaglul H, Brown R. Propofol associated hiccups and treatment with lidocaine. Anesth Analg 2008;107: 1757-1758.

67. Cohen SP, Lubin E, Stojanovic M. Intravenous lidocaine in the treatment of hiccup. South Med J 2001;94:1124-1125.

68. Okuda Y, Kitajima T, Asai T. Use of a nerve stimulator for phrenic nerve block in treatment of hiccups. Anesthesiology 1998;88:525527.

69. Payne BR, Tiel RL, Payne MS, Fisch B. Vagus nerve stimulation for chronic intractable hiccups. Case report. J Neurosurg 2005;102:935937.

70. Kang KN, Park IK, Suh JH, Leem JG, Shin JW. Ultrasound-guided pulsed radiofrequency lesioning of the phrenic nerve in a patient with intractable hiccup. Korean J Pain 2010;23:198-201.

71. Schiff E, River Y, Oliven A, Odeh M. Acupuncture therapy for persistent hiccups. Am J Med Sci 2002;323:166-168.

72. Chang CC, Chang YC, Chang ST, et al. Efficacy of near-infrared irradiation on intractable hiccup in custom-set acupoints: evidencebased analysis of treatment outcome and associated factors. Scand J Gastroenterol 2008;43:538-544.

73. Brimacombe J, Keller C. Inhibition of hiccups by the laryngeal mask airway is ineffective. Anaesthesia 2004;59:1144.

74. Morris L, Marti J, Ziff D. Intractable hiccoughs in pregnancy. J Obstet Gynaecol 2004;24:474.

75. Heymann WR. The Heimlich maneuver for hiccups. J Emerg Med 2003;25:107-108. 